\title{
Effects of Short-message Notifications on Type 2 Diabetes Management in Middle-aged Turkish Patients: A Randomized Trial
}

\author{
Bernard Tahirbegolli1,2®, Iliriana Alloqi Tahirbegolli3,4®, Ramazan Çakmak ${ }^{5}$, Cemile İdiz ${ }^{6}$, \\ Sabanur Çavdar ${ }^{\top}$, Elif Bağdemir8®, Suphi Vehid 90
}

\author{
${ }^{1}$ Department of Public Health, Institute of Health Sciences, İstanbul University, İstanbul Turkey \\ ${ }^{2}$ Department of Management of Health Institutions and Services, Heimerer College, Prishtina, Kosovo \\ ${ }^{3}$ Medical Pharmacology and Clinical Pharmacology Department, Institute of Health Sciences, İstanbul University, İstanbul, Turkey \\ ${ }^{4}$ Department of Nursing, Heimerer College, Prishtina, Kosovo \\ ${ }^{5}$ Division of Endocrinology and Metabolic Diseases, Department of Internal Medicine, Başaksehir City Hospital, İstanbul, Turkey \\ ${ }^{6}$ Division of Endocrinology and Metabolic Diseases, Department of Internal Medicine, İstanbul Faculty of Medicine, İstanbul University, İstanbul, Turkey \\ ${ }^{7}$ Umraniye District Health Directorate, Ministry of Health of Turkey, İstanbul, Turkey \\ ${ }^{8}$ Division of Endocrinology and Metabolic Diseases, Department of Internal Medicine, İstanbul Faculty of Medicine, İstanbul University, İstanbul, Turkey \\ ${ }^{9}$ Department of Public Health, Cerrahpaşa Faculty of Medicine, İstanbul University-Cerrahpaşa, İstanbul Turkey
}

\section{To the Editor,}

Patients with type 2 diabetes mellitus (T2DM) have a management plan that aims to improve their health and quality of life by changing their lifestyle, keeping their glycemic control as close to normal as possible, ensuring their regular pharmacological treatment adherence, and preventing diabetic complications. This study aimed to determine the role of short-message (SMS) technology in raising awareness of medication adherence (MA), physical activity (PA), fasting blood glucose (FBG), and glycated hemoglobin A (HbA1c) readings. This single-blinded, randomized, controlled study included 69 patients, which initially began with 125 patients (SMS group $\mathrm{n}=65$ and control group $\mathrm{n}=60$ ). Of these 69 patients, 43 (20 [46.5\%] males and 23 [53.5\%] females) were randomized to the SMS group (intervention group) and 26 (14 [53.8\%] males and $12[46.2 \%]$ females) were present in the control group who completed their third controls at 6 months. Using the G-power program in the analysis of variance axis for calculating three repeated measurements, the research sample was estimated with 43 participants in group 1 and 26 participants in group 2, with an effect size of 0.25 and $0.05 \alpha$ and a power of $0.991-\beta$. Patients without surgery or cardiac incident in the previous 3 months, between the ages of 40 and 64 years, diagnosed with T2DM in the previous 1-10 years, and with oral antidiabetic therapy for at least 1 year were included in the study. Patients in the intervention group received 3-4 informative messages (SMS) per week in addition to conventional treatment for 6 months, whereas patients in the control group received standard care. The study was conducted at Istanbul University Medical Faculty Hospital's Diabetes Polyclinic, and prior to enrolling in the study, all participants signed the informed consent forms. The Ethics Committee of the Cerrahpaşa Medical Faculty, İstanbul University, approved the study protocol (file number 83045809/604.01/02-380913). This study was registered at ClinicalTrials.gov (\#NCT04733612).

FBG, HbA1c, systolic and diastolic blood pressure, waist/hip ratio, PA as measured by the International Physical Activity Questionnaire $(\mathrm{IPAQ})^{1}$, and MA as measured by the Morisky Medication Adherence Scale- 8 (MMAS- 8$)^{2}$ were the primary outcomes, which were assessed every 3 months.

The International Business Machines Statistical Package for the Social Sciences v21.0 package program was used to analyze the data. Chi-square, Independent Groups t-test, or Mann-Whitney U Test, GLM Repeated Measures, or Friedman Repeated Measures Analysis were used to assess the differences and relationships between the variables. The P-values of $<0.05$ were regarded as statistically significant.

No statistically significant change was found in FBG levels in both the groups at 6 months $(P>0.05)$. In the intervention group, 
TABLE 1. Fasting Blood Glucose, Glycated Hemoglobin A, Physical Activity, Medication Adherence Scores, Blood Pressure, Heart Rate, Body Mass Index, Body Fat Ratio, And Waist/Hip Ratio of Volunteers By Groups According to Assessments

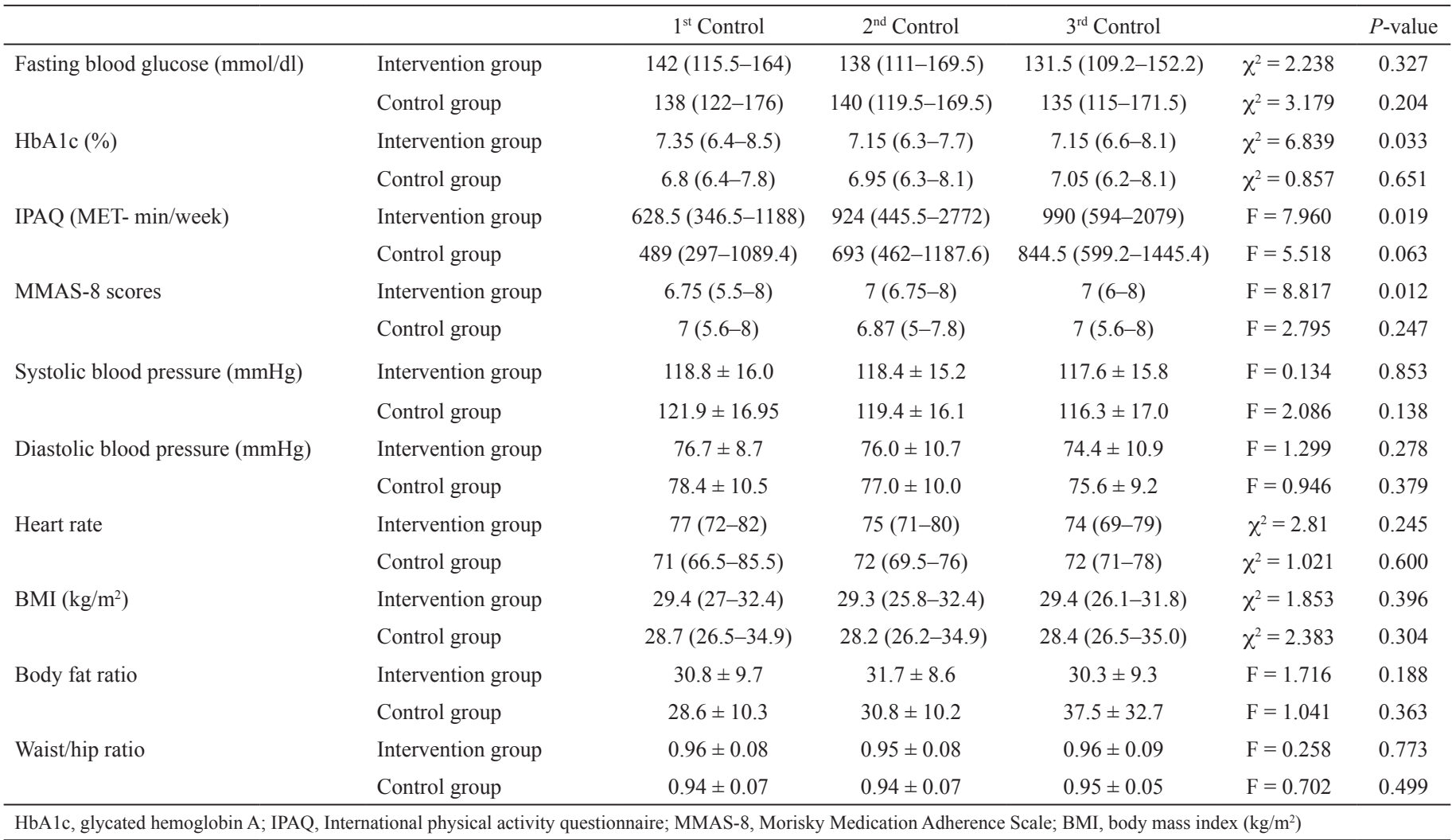

a statistically significant improvement was found in $\mathrm{HbA} 1 \mathrm{c}$ percentages and PA levels $(P<0.05)$. A statistically significant increase in drug adherence (MMAS- 8 score) was found throughout the 6-month intervention group $(P<0.05)$ using Friedman's Repeated Measures chi-square test. After 6 months, no statistically significant difference was found in the systolic and diastolic blood pressures, heart rate, body mass index, waist/hip ratio, and body fat ratio in both the groups $(P>0.05)$ (Table 1$)$. Our findings on FBG, $\mathrm{HbA1c}$, and MMAS-8 scores were consistent with those reported in previous studies by Sezgin et al. ${ }^{3}$, Islam et al., and Abbas et al. ${ }^{5}$

In conclusion, our results demonstrated that SMS notifications improved metabolic control, PA, and MA in middle-aged Turkish patients with T2DM. SMS notifications are a useful and effective tool for managing and monitoring chronic diseases, such as T2DM, which necessitate lifestyle changes.

Ethics Committee Approval: The Ethics Committee of the Cerrahpaşa Medical Faculty, Istanbul University-Cerrahpaşa, 83045809/604.01/02-380913.

Patient Consent for Publication: Informed consent was obtained from all individual participants included in the study.

Data Sharing Statement: The data that support the findings of this study are available from the corresponding author upon reasonable request.

Author Contributions: Design - B.T., I.A.T., R.Ç., C.İ., E.B., S.Ç., S.V.; Data Collection or Processing - B.T., R.Ç., C.İ., E.B.; Analysis or Interpretation - B.T., I.A.T., S.Ç., S.V.; Drafting - B.T., I.A.T., R.Ç., C.İ., E.B., S.Ç., S.V.; Revision - B.T., S.V.
Conflict of Interest: No conflict of interest was declared by the authors.

Funding: The present work has been supported by the Research Fund of Istanbul University, project No: 20135. The Research Fund of Istanbul University had no role in design and conduct of the study; collection, management, analysis, and interpretation of the data; and preparation, review, or approval of the manuscript.

Acknowledgement: The authors would like to thank Prof. Dr. Ethem Erginöz (Cerrahpasa Medical Faculty, Department of Public Health), Prof. Dr. Safinaz Yıldız (Istanbul Medical Faculty, Department of Sports Medicine), Prof. Dr. Bülent Bayraktar (Istanbul Medical Faculty, Department of Sports Medicine), Dr. Ufuk Değirmenci (Istanbul Medical Faculty, Department of Sports Medicine), Prof Dr. İlhan Satman (Istanbul Medical Faculty, Department of Endocrinology and Metabolism), and Prof. Dr. Yağız Üresin (Istanbul Medical Faculty, Department of Medical Pharmacology and Clinical Pharmacology) for their contribution and support.

\section{REFERENCES}

1. Craig CL, Marshall AL, Sjöström M, et al. International physical activity questionnaire: 12-country reliability and validity. Med Sci Sports Exerc. 2003;35:1381-1395. [CrossRef]

2. Morisky DE, DiMatteo MR. Improving the measurement of self-reported medication nonadherence: response to authors. J Clin Epidemiol. 2011;64:255. [CrossRef]

3. Sezgin H, Cinar S. Follow-up of Patients with Type 2 Diabetes via Cell Phone: Randomized Controlled Trial. MÜSBED. 2013;3:173-183. [CrossRef]

4. Abbas BB, Al Fares A, Jabbari M, El Dali A, Al Orifi F. Effect of mobile phone short text messages on glycemic control in type 2 diabetes. Int $J$ Endocrinol Metab. 2015;13: e18791. [CrossRef]

5. Islam SM, Niessen LW, Ferrari U, Ali L, Seissler J, Lechner A. Effects of Mobile Phone SMS to Improve Glycemic Control Among Patients With Type 2 Diabetes in Bangladesh: A Prospective, Parallel-Group, Randomized Controlled Trial. Diabetes Care. 2015;38:e112-113. [CrossRef] 